\title{
Clericalismo y anticlericalismo en la Constitución de 1917: un acercamiento al problema a través de los debates del Constituyente
}

Clericalism and anti-clericalism in the Constitution of 1917: an approach from the debates of the constituent congress

Juan GONZÁLEZ MORFÍN

Universidad Panamericana, México jgonzalezmorfin@yahoo.com.mx

Abstract: In February 1917, a constituent Assembly endowed Mexico with a new constitution. It included numerous provisions that restricted religious freedom. The analysis of the debates makes it possible to know that at the same time that the Catholic Church was attacked, many of its proposals in social matters were collected and a language similar to the ecclesiastical was used in the arguments, which allows to point out a new kind of clericalism within the anti-clericalism of the constituent.

Keywords: Revolution; law; Catholic Church; persecution; language.
Resumen: En febrero de 1917 una asamblea constituyente dotó a México de una nueva constitución. En ella se incluyeron numerosas disposiciones que coartaban la libertad religiosa. El análisis de los debates permite conocer que al mismo tiempo que se atacaba a la Iglesia católica, se recogían muchas de sus propuestas en materia social y se utilizaba en las argumentaciones un lenguaje parecido al eclesiástico, lo que permite señalar una nueva especie de clericalismo dentro del anticlericalismo del Constituyente.

Palabras clave: Revolución; ley; Iglesia católica; persecución; lenguaje.

\section{INTRODUCCIÓN}

Entre el 21 y el 30 de noviembre de 1916, se llevaron a cabo 11 juntas de preparación para establecer los integrantes y procedimientos para el Congreso que debería dar al país una nueva Constitución. El 1 de diciembre de ese mismo año se celebró la sesión inaugural y comenzaron los trabajos legislativos con gran intensidad, pues los diputados se habían propuesto que la nueva Carta magna estuviera terminada de modo que pudiera ser promulgada el 5 de febrero de 1917, coincidiendo con la fecha en la que años antes lo había sido la Constitución de 1857. De esa forma, entre el 1 de diciembre de 1916 y el 31 de enero de 1917, el 
constituyente efectuó 66 sesiones y trabajó mañana y tarde prácticamente todos los días. El constituyente anterior había trabajado casi un año en la elaboración de la Constitución del 57 y había tenido 209 sesiones.

De un periodo de trabajo intenso, aunque breve, surgió la nueva constitución que, junto con artículos muy avanzados en materia social y que respondían a los reclamos populares, contenía otros claramente orientados a coartar el ejercicio de la práctica religiosa, y que afectaban de un modo singular a la Iglesia católica, cuya fe era profesada por la mayoría de los habitantes del país, pues, de acuerdo al censo de 1910, los católicos constituían el $99 \%{ }^{1}$.

El Diario de los debates del Congreso nos permite adentrarnos en el proceso de redacción definitiva de esos artículos, así como conocer las argumentaciones de quienes los propusieron.

En este trabajo se ofrecerá, de manera rápida, un esbozo de lo que acontecía en la discusión de esas leyes que, en pocos años, serían en buena parte el detonador de la lucha por la libertad religiosa emprendida por los «cristeros». A través de los párrafos escogidos se buscará un acercamiento a la mentalidad anticlerical en el fondo y clerical en la forma de algunas discusiones en las que se alcanza a apreciar un posible intento de sustitución de una forma de pensar a la que se acusaba de sectaria, por otra no menos sectaria, cuya principal virtud era haber sido emanada por el constituyente. Se comenzará por describir los antecedentes inmediatos a la asamblea de Querétaro, para luego ampliar un poco más cuál había sido la propuesta de los católicos a la «cuestión social»y, finalmente, retomar la línea central de esta exposición, basada principalmente en los debates del constituyente. Se buscará con esto explorar si en el fondo o en la forma de las argumentaciones, por más que reiteradamente se atacaba a la Iglesia y a sus representantes, se encuentra alguna relación con los postulados eclesiásticos que, ya anteriormente, se habían venido promoviendo por los católicos.

\section{TINTES TRÁGICOS DEL ANTICLERICALISMO EN MÉXICO}

En el siglo XIX se había vivido una versión atenuada, en realidad muy diferente, del anticlericalismo revolucionario que llevó a algunos constituyentes del 17 a posturas que caen en la estridencia. En efecto, las críticas principales a la

1 En 1910, en México había 15,160,369 habitantes, de los cuales 15,033,176 se declararon católicos, lo que significa un $99.16 \%$ (cfr. INEGI, Estados Unidos Mexicanos, Cien años de censos de población, INEGI, Aguascalientes, 1996, p. 97). 
Iglesia procedían de un liberalismo económico que veía en la acumulación del capital y de bienes inmuebles un obstáculo real al progreso económico ${ }^{2}$. También, siguiendo la tendencia de algunos ilustrados, otros anticlericales de cepa, como Ignacio Ramírez, alias el Nigromante, se dedicaron a cuestionar los dogmas de la Iglesia, los Evangelios e, incluso, la existencia de Dios 3 . Otros más se centraron en la promoción de la tolerancia de cultos en un país en que constitucionalmente no se admitía otra religión que no fuera la católica ${ }^{4}$. De hecho, aunque ampliamente discutida durante la elaboración de la carta magna de $1857^{5}$, la libertad de cultos no fue aprobada sino dos años más tarde: «El estado de nuestra sociedad está por desgracia muy distante de ser cual debiera, para que reformas de tan alta importancia como la que se discute, pudieran plantearse sin graves y probables peligros $»^{6}$, argumentó José María Lafragua, uno de los más connotados liberales. Sin embargo, se había cumplido con un objetivo principal de los constituyentes liberales del 57: dejar incoados en la carta magna los principios de una separación formal entre la Iglesia y el Estado, que sucedería apenas unos años después con las Leyes de Reforma.

$\mathrm{El}$ anticlericalismo de esta época, interesado sobremanera en desposeer a la Iglesia de todos sus haberes, centró en buena parte sus ataques en este tema utilizando incluso argumentos de los padres de la Iglesia sobre la inconveniencia de poseer bienes materiales ${ }^{7}$. Sin embargo, ya se encuentran en éste algunas manifestaciones externas de emulación cívica de conceptos, modos y rituales religiosos. Ejemplo de esto fueron los llamados catecismos, como el Catecismo politico de Derechos Constitucionales, de Nicolás Pizarro, utilizado para adoctrinar al pueblo ${ }^{8}$.

Por otra parte, durante el largo periodo de la dictadura porfirista, el presidente Díaz evitó la aplicación estricta de las leyes de Reforma, por lo que las manifestaciones anticlericales se dieron únicamente a nivel de propuestas, tanto en la prensa

2 Cfr. Guillermo PRIETO, Lecciones elementales de economía política, Imprenta del Gobierno, en Palacio, a cargo de José María Sandoval, México, 1871.

3 Nora PÉREZ RAYÓN, Liberalismo, anticlericalismo y ateísmo en México. Ignacio Ramírez, El Nigromante, en Franco SAVARINO y Andrea MUTOLO (coords.), El anticlericalismo en México, Miguel Angel Porrúa, México, 2008, pp. 386-388.

4 Cfr. Melchor OCAMPO, Obras completas, t III, F. Vázquez Editor, México, 1901, pp. 662-671.

5 Cfr. José Luis SoberANES FERNÁNDEZ, Una aproximación al constitucionalismo liberal mexicano, Porrúa, México, 2015, pp. 65-87.

6 Ibid., p. 81.

7 Cfr. El Monitor Republicano, 26 de abril de 1856, p. 3.

8 Cfr. Nicolás PizarRo, Obras completas, t. I, Catecismos, UnAM, México, 2005. 
como en algunos discursos oficiales. A la caída de Díaz, los presidentes Francisco León de la Barra y Francisco I. Madero, durante sus breves periodos, ni se preocuparon de las Leyes de Reforma, ni fomentaron las disposiciones anticlericales.

Habría que esperar hasta la segunda etapa de la Revolución, esto es, una vez asesinado el presidente Madero, para observar una verdadera persecución de palabra y obra en contra del «elemento clerical» por parte de muchos jefes revolucionarios. Esta ha sido motivo para numerosos estudios que han pretendido desentrañar las raíces ideológicas de esta situación?. Particularmente, han causado interés tanto el caudal de leyes anticlericales o, más bien dicho, antirreligiosas que se dictaban por los diferentes poderes constituidos en un país predominantemente católico, como las llamadas campañas de desfanatización que tuvieron lugar como consecuencia de los gobiernos revolucionarios durante un arco de tiempo no pequeño, entre los años 1914 y $1938^{10}$.

Álvaro Matute no duda llamar «quinta revolución» a la que se significó por sus excesos en contra de la Iglesia católica ${ }^{11}$. Las otras cuatro revoluciones habrían sido la obrera, la agraria, la cultural y la política. El anticlericalismo no es incluido en la última, pues esta se caracterizó por su intención democrática, y este «no puede formar parte de la revolución democrática, entre otras cosas por su contenido antidemocrático, en el sentido de ser una restricción impuesta por el Estado hacia la sociedad» ${ }^{12}$.

Esa restricción se manifestó de manera muy variada en la época preconstitucional. Conforme el ejército carrancista avanzaba, eran más las demostraciones

9 Entre las recopilaciones de artículos orientados a tratar este tema, se encuentran Franco SAVARINO y Andrea MUTOLO (coords.), El anticlericalismo..., op. cit.; Matthew BUTLER (ed.), Faith and Impiety in Revolutionary Mexico, Palgrave MacMillan, New York, 2007. Para una mejor comprensión del anticlericalismo véase también Jean MEYER, La Cristiada. 2. El conflicto entre la Iglesia y el Estado 1926/1929, Siglo XXI, México, 1973, pp. 193-206; ID., «El anticlerical revolucionario, 1910-1940. Un ensayo de empatía histórica», en Ricardo Ávila Palafox, Carlos MarTíneZ ASSAD y Jean MEYER (coords.), Las formas y las politicas del dominio agrario, Universidad de Guadalajara, Guadalajara, 1992, pp. 284-304; José Luis SOBERANES FERNÁNDEZ, «El anticlericalismo en el Congreso Constituyente de 1916-1917», en Cuestiones Constitucionales. Revista Mexicana de Derecho Constitucional, 36 (2017/1), pp. 199-241.

10 Es por eso que afirma Bantjes: «Between 1914 and 1938, anticlericalism and defanaticization constitued central aspects of nationwide cultural revolution» (Adrian A. BANTJES, The Regional Dynamics of Anticlericalism and Defanaticization in Revolutionary Mexico, en Matthew BUTLER [ed.], Faith..., op. cit., p. 111).

11 Cfr. Álvaro MATUTE, Los orígenes del revisionismo historiográfico de la revolución mexicana, en Aproximaciones a la bistoriografía de la revolución mexicana, Instituto de Investigaciones Históricas, UNAM, México, 2005, pp. 39-53; ID., «El anticlericalismo, ¿quinta revolución?», en Franco SAVARINO y Andrea MUTOLO (coords.), El anticlericalismo..., op. cit., pp. 29-37.

12 Ibid., p. 31. 
de aversión al clero con las que nos encontramos; muchas de ellas se plasmaron en decretos de los jefes militares que iban ocupando las ciudades. Entre estas, dos pueden servir de ejemplo: la promulgada el 14 de junio de 1914 por el general constitucionalista Antonio I. Villarreal y cuyos alcances se extendían a todo el estado de Nuevo León, y la dictada en septiembre de ese mismo año por el general Francisco Murguía para el estado de México.

En la primera de estas regulaciones existe una «exposición de motivos» que sintetiza bien el espíritu anticlerical de esos momentos:

Las dictaduras pretorianas y clericales de Porfirio Díaz y Victoriano Huerta contra los que ha venido luchando victoriosamente el pueblo en estos últimos años, han tenido toda la simpatía y todo el apoyo de la Iglesia Católica mexicana que siempre ha procurado evitar que se haga luz en los cerebros de los oprimidos y ha querido remachar las cadenas de los que sufren. El clero ha tenido bendiciones para los crímenes y corrupciones repugnantes de Huerta, y ha trabajado, afortunadamente sin éxito, para que la masa popular creyente se levantara contra el movimiento constitucionalista que viene a redimirlo ${ }^{13}$.

Y, después de aclarar que se permitirá abrir al culto solamente cinco iglesias en todo Monterrey, observando unos horarios preestablecidos, el decreto ordenaba:

1. Se expulsa del Estado de Nuevo León a todos los sacerdotes católicos extranjeros y a todos los jesuitas de cualquier nacionalidad que sean.

2. De los restantes sacerdotes católicos se expulsa a todos los que no comprueben debidamente y den su abstención de asuntos políticos.

3. Las iglesias estarán abiertas desde las 6 a.m. hasta la 1 p.m. En ellas sólo podrán oficiar los sacerdotes que tengan permiso, por haber hecho la comprobación a que se refiere el artículo anterior.

4. Se prohíben solemnemente los confesionarios y las confesiones.

5. Se prohíbe la entrada del público a la sacristía.

6. Las campanas de los templos se usarán solamente para festejar las fiestas patrias y los triunfos de las armas constitucionalistas.

7. Se clausurarán todos los colegios católicos que no se sometan estrictamente a los programas y textos oficiales (...).

8. Las infracciones de cualquiera de estas disposiciones se castigarán con multa de 10 a 500 pesos o arresto de dos a cuatro meses $(. . .)^{14}$.

13 Decreto del gobernador de Nuevo León, Antonio I. Villarreal, del 14 de julio de 1914, en Esteban J. PALOMERA, La obra educativa de los jesuitas en Guadalajara, 1586-1986, Instituto de Ciencias ITESO - UIA, Guadalajara, 1986, p. 233.

14 Ibid., pp. 234-235. 
En cuanto al decreto del general Murguía, parecido en algunos de sus términos, conviene solo mencionar el modo en que prohibía la confesión: «queda prohibida de una manera absoluta la práctica de la confesión. Para la mejor observancia de esta prescripción, los templos no podrán abrirse más que cada ocho días, a la hora de las misas». ${ }^{15}$ En estas disposiciones, también se limitaba el número de sacerdotes que podían ejercitar su ministerio a solamente uno por localidad, se prohibía usar atuendo religioso y se proscribía cualquier tipo de ceremonia religiosa, exceptuadas dos misas el domingo.

Este tipo de reglamentaciones constituyeron un ensayo de lo que sería el artículo 130 de la Constitución del 17, en el que se facultó a las legislaturas de los estados a reducir arbitrariamente el número de sacerdotes.

De estos desplantes anticlericales, daba cuenta a Benedicto XV el arzobispo José Mora y del Río en una carta escrita en 1916, poco antes de que iniciara el Constituyente de Querétaro, en la que también lo prevenía acerca de la orientación anticlerical que se veía venir en algunos artículos: «Es más que cierto que esta Revolución socialista, buscando la reforma y la restauración de los asuntos públicos, como consta plenamente, a través de la violencia y de la subversión nefasta de todo el orden, ha establecido perseguir la religión hasta extinguirla» ${ }^{16}$. Y, al final de la carta, señalaba cuáles serían los cambios que por testigos dignos de confianza se sabía que habrían de intentar los revolucionarios:

I. En materia de enseñanza:

1. La enseñanza primaria y normal será monopolio del Gobierno.

2. La enseñanza primaria será obligatoria, gratuita y laica para niños y niñas.

3. Las escuelas profesionales serán intervenidas por el Gobierno Federal, quien será el que precise los requisitos conforme a los cuales deben expedirse los títulos.

4. Los profesores serán inamovibles.

5. Las personas dependientes de asociaciones religiosas no podrán dedicarse a la enseñanza.

6. No se tolerarán seminarios religiosos.

7. No se tolerarán escuelas dependientes de Asociaciones Religiosas.

15 Decreto del general Francisco Murguía, del 30 de septiembre de 1914, en Félix NAVARRETE, De Cabarrús a Carranza, La legislación anticatólica en México, Jus, México, 1957, pp. 136-137.

16 José MORA Y DEL RíO, Carta a Benedicto XV, 5-VIII-1916, en Archivo de la Arquidiócesis de Guadalajara, sección gobierno, serie obispos: Francisco Orozco y Jiménez, años 1912-1918, sin número de folio: «Certo certius haec Revolutio, socialisticam publicae rei reformationem et restaurationem intentans, ut id plene attingatur, per vim et nefas omne subverso omni ordine, Religionem ipsam persequi statuit, si fieri possit, usque ad interncecionem (sic)». El documento completo se puede consultar en Juan GONZÁLEZ MORFÍN, La situación de la Iglesia católica en los años 1914-1916 en una carta que nunca llegó al papa, en Relaciones Estudios de Historia y Sociedad, 149 (inv. 2016), pp. 139-166. 
II. En materia de religión:

1. No se tolerarán asociaciones dependientes de Asociaciones Extranjeras.

2. No se permitirá que los encargados de los servicios religiosos tengan como único medio de subsistencia la caridad pública.

3. Los sacerdotes católicos y los miembros de algún otro culto religioso no tendrán derecho a votar ni a ser votados.

4. No se tolerará el celibato en las personas encargadas de servicios religiosos.

5. No se tolerará la confesión.

6. No se permitirá que tengan lugar cultos religiosos en los días y horas de trabajo.

7. Habrá un Interventor del Gobierno que vigile por el uso de las limosnas recogidas para el fomento de las instituciones religiosas.

III. En materia de reformas sociales:

El Divorcio ${ }^{17}$.

En otra parte de la carta el arzobispo de México citaba un párrafo de un folleto anticlerical, supuestamente apoyado y difundido por el gobierno en el que se decía lo siguiente:

Queremos perseguir la bandada de Buitres con sotana, hasta aniquilarla y confundirla; hasta dejarla impotente, exánime muerta. No queremos solamente derrotarla: queremos acabar con ella; no queremos humillarla simplemente, queremos extinguirla; no queremos que capitule, podría resurgir; queremos desaparecerla para siempre; no queremos conformarnos con que abandone el territorio de México, tenemos que perseguirla por el orbe hasta acabar con ella. Es guerra a muerte, sin cuartel, sin misericordia y sin perdón ${ }^{18}$.

En ese mismo documento, Mora y del Río señalaba que, uno de los pretextos que se estaban usando para perseguir a la Iglesia católica, era el apoyo que la jerarquía había dado hasta cierto punto al Partido Católico Nacional, apoyo que fue siempre dentro del marco legal de la Constitución vigente, de cuyo marco tampoco se apartaron nunca los que integraban dicho partido, «y ahora los carrancistas, para cohonestar la persecución, acusan al clero mexicano como si hubiera actuado en contra de las leyes nacionales» ${ }^{19}$.

Efectivamente, la actuación efímera de un grupo de católicos oficiales en la política, había servido para fundamentar muchos de los ataques al clero. Refirién-

17 Ibid. (como un apéndice de la carta, se halla escrito en español).

$18 \mathrm{Ibid}$. (intercalado en el texto latino, este fragmente se cita en español como procedente de la revista El Bonete).

19 Ibid.: «Ac Carrancistae, ad persecutionem cohonestandam, clerum mexicanum nunc accusant quasi contra leges nationales egissent». 
dose al anticlericalismo que, si bien unos años después del constituyente, procedía del ala obrera del gobierno revolucionario, Álvaro Matute señala lo siguiente:

El anticlericalismo obrero fue patente en la Confederación Regional de Obreros Mexicanos (CROM) y en el Partido Laborista originado por ella. Tengo como hipótesis que tal manifestación contraria a la Iglesia católica se debió en gran parte al buen desarrollo que tuvo la doctrina social de la Iglesia, manifiesta en los congresos católicos y en el sindicalismo derivado de ellos, que antes de la guerra cristera alcanzó un elevado número de afiliados ${ }^{20}$.

Es por ello que, para los fines de este estudio, conviene recordar un poco cómo se desarrolló este movimiento social católico.

\section{LA IGLESIA Y EL MOVIMIENTO OBRERO}

La segunda mitad del siglo XIX, que a nivel internacional marcó hitos importantes en la aspiración de muchos obreros no sólo por rescatar derechos que se les desconocía en el terreno laboral, sino, en algunos casos, incluso por recibir un trato acorde a su dignidad humana, no tuvo en México los mismos colores ni las mismas demandas que los países industrializados, sencillamente porque la realidad del país era diferente ${ }^{21}$.

En efecto, lo que domina en el porfiriato es el mundo de los pequeños talleres, en los que obreros sui generis trabajan para un patrón y fácilmente se agrupan por gremios para obtener ventajas mutuas. A estos, habría que sumarle todo aquel

20 Álvaro MATUTE, El anticlericalismo..., op. cit., pp. 36-37. Efectivamente, el discurso mantenido por el PCN y los logros obtenidos a favor del obrero, lo convertían en un adversario temible para el incipiente corporativismo revolucionario. A modo de ejemplo: «Nadie antes que nosotros, como lo prueban los congresos católicos de Puebla, de Morelia, de Guadalajara, de Oaxaca, de Zamora, de León y Tulancingo, se ha ocupado en el mejoramiento de la clase obrera, y al bajar al estadio de la política, organizados en Partido, nada queremos tanto como el respeto del derecho del pobre, como la mejora de su vida, como la perfección de su alma, que lo hace a un mismo tiempo digno y humilde, valiente contra el abuso y sumiso para la autoridad, celosísimo del derecho propio, pero eminentemente respetuoso del derecho ajeno» (Gabriel FERNÁNDEZ DE SOMELLERA et al., Manifiesto, 5-XII-1912, en Román IGLESIas GONZÁLEZ [comp.], Planes políticos, proclamas, manifiestos y otros documentos de la Independencia al México moderno, 1812-1940, Instituto de Investigaciones Jurídicas [UNAM], México, 1998, p. 640).

21 Nos sirve como dato que apoya esta hipótesis el hecho de que la primera asociación de obreros, surgida en 1872 con el nombre de Gran Círculo de Obreros libres bajo la influencia de los exiliados franceses, no pasó de ser una federación de asociaciones mutualistas que en 1880 votó su anexión al gobierno de Porfirio Díaz y, diez años más tarde, desapareció (cfr. François Xavier GuERRA, México: del Antiguo Régimen a la Revolución, t. I, Fondo de Cultura Económica, México, 1988, p. 176). 
que vivía de su trabajo, desde el panteonero hasta los mineros de empresas metalúrgicas, que justo al final de la época de don Porfirio tuvieron su auge.

Sin embargo, sugiere François Xavier Guerra, «en la época porfirista sólo se encuentra a los verdaderos obreros, y todavía con una extracción rural muy próxima, en la industria textil, y sobre todo en la región de Puebla-Tlaxcala-Orizaba, y en algunas ciudades de La Laguna, en Coahuila» ${ }^{22}$.

Aun así, la realidad tanto de unos como de otros era ciertamente precaria, y quienes primero acudieron a buscar algún tipo de solución, según se aprecia en la historia, fueron los pastores católicos. Un ejemplo de esto lo apreciamos en la notable difusión que tuvo la encíclica Rerum novarum, del pontífice romano León XIII, ampliamente conocida en México el mismo año de su publicación (1891), en tanto que el Manifiesto del Partido Comunista, conocido en los ambientes obreros europeos desde 1848, no fue publicado en México sino hasta $1884^{23}$.

Del estudio y aplicación práctica de la encíclica papal, surgieron y en muy poco tiempo se encontraban extendidos por los lugares más recónditos del país los círculos de obreros católicos, los sindicatos católicos y otras agrupaciones de ayuda mutua entre $\left\langle\right.$ hermanos» ${ }^{24}$. Así, se lee por ejemplo en un documento de una de estas asociaciones en Zapotlán el Grande, Jalisco:

En el informe rendido por el presidente de la Unión Católica en septiembre de 1899, correspondiente al año anterior, se señala, entre otras cosas, el socorro dado a 247 socios que por enfermedad «tuvieron que acudir al auxilio de sus hermanos»; que se gastaron en medicinas 11.54 pesos, en honorarios al médico 80 , en una función religiosa y en sufragios por las almas de los socios difuntos 40.75 pesos, etc. Como parece ser natural, las expresiones de agradecimiento al párroco habían de estar presentes «por su infatigable celo en procurar el bien de sus feligreses, con especialidad, el bien de la clase obrera, imitando en esto al egregio Pontífice León XIII» ${ }^{25}$.

Cuando ya el país se encontraba lleno de estos focos de irradiación de la doctrina social promovida por la Iglesia, algunos prelados vieron la conveniencia

22 Ibid., p. 175.

23 Cfr. Jorge ADAmE GODDARD, Influjo de la Doctrina Social Católica en el Artículo 123 Constitucional, en Boletín Mexicano de Derecho Comparado, 47 (1983), p. 423; Francisco BARBosa GuZMán, El arzobispo fesús Ortiz, «padre de los obreros», en Boletín Eclesiástico, VIII (2014/3), pp. 41-56.

24 Sobre el sindicalismo católico, se puede ver, José Manuel LASTRA LASTRA, El sindicalismo en México, en Anuario Mexicano de Historia del Derecho, XIV (2002), pp. 51-53; Manuel CEballos RAMÍREZ, Sindicalismo Católico en México, en Historia mexicana, XXXV (1986/4), pp. 621-673.

25 Francisco BARBOSA GUZMán, El arzobispo Jesús Ortiz..., op. cit., pp. 50-51. Situaciones parecidas en otra región se pueden analizar en Eduardo CAMACHO MERCADO, Frente al hambre y al obús: Iglesia y feligresía en Totatiche y el Cañón de Bolaños, 1876-1926, CULagos / Departamento de Estudios Históricos de la Arquidiócesis de Guadalajara, Lagos de Moreno-Guadalajara, 2014. 
de convocar congresos en los que se discutieran temas sociales, junto con otros de carácter más bien pastoral, con el fin de establecer algunas líneas de acción a seguir en todo el territorio nacional.

El arzobispo de Guadalajara, José de Jesús Ortiz López, explicaba de la siguiente manera lo que debía entenderse por «congreso católico»: «Un congreso católico no es a la verdad una asamblea política, ni por las materias de que se ocupa y los fines que se propone, ni por la calidad y el mandato de las personas que lo constituyen», sino más bien «la pacífica reunión de católicos distinguidos por su piedad y su saber, así sacerdotes como seglares, convocados bajo los auspicios del Episcopado y en ejercicio de un derecho garantizado por la ley política del país, para deliberar y cooperar en la medida de sus fuerzas a la realización de los grandes fines que la Iglesia persigue en su benéfica acción sobre la sociedad $»^{26}$.

En ese mismo documento, tomando en cuenta de que antes ya se habían efectuado otros dos congresos, el prelado invitaba a tener paciencia si los resultados de éstos no se veían inmediatamente:

Hase objetado, sin embargo, en contra de los congresos católicos, a lo menos entre nosotros, la ineficacia de sus acuerdos en el orden práctico.

Porque no vemos surgir como por encanto en pos de la celebración de un congreso, las escuelas, los círculos de obreros y demás instituciones preconizadas por los congresistas, inferimos que todo se reduce a la estéril exposición de postulados cuya importancia nadie desconoce, o a varios alardes de erudición y elocuencia (...).

La madurez del fruto, o sea la perfección de la obra buena, es producto de la acción combinada de la Divina Gracia y de la libre cooperación de la voluntad; requiérese tiempo y perseverancia en los propósitos, gran suma de esfuerzos, de luchas y sacrificios (...).

No debemos, pues, desalentarnos si los resultados inmediatos no corresponden acaso a las vivas ansias del celo. En las obras emprendidas para la gloria de Dios, no es el éxito del mañana lo que se nos pide, sino el trabajo del día ${ }^{27}$.

Los católicos, siguiendo a algunos prelados entusiasmados con mejorar las condiciones de los obreros a partir de propuestas concretas, siguieron participando en este tipo de reuniones y, así, a los congresos católicos de Puebla (1903), Morelia (1904), Guadalajara (1906) y Oaxaca (1909), se sumaron los congresos agrícolas de Tulancingo (1904, 1905 y 1906), las semanas católico-sociales de León (1908), de México (1910 y 1911) y Zacatecas (1912), así como las «dietas» de México (1911) y

26 José de Jesús OrTiz López, Carta Pastoral con motivo del Congreso Eucarístico, septiembre de 1906, en Boletín Eclesiástico y Científico (1906-1907), p. 326 (el subrayado es nuestro).

27 Ibidem. 
de Zamora (1913), estas últimas reuniones eran organizadas por la Confederación Nacional de Círculos Católicos de Obreros, pero tanto en estas como en las anteriores, participaban obispos, sacerdotes y laicos. Por darnos una idea de la proporción, en el congreso de Guadalajara en 1906 participaron cincuenta y cinco laicos y noventa y siete eclesiásticos, de estos últimos, dieciséis eran obispos ${ }^{28}$.

Algunas de las resoluciones de estas reuniones de trabajo, cristalizaron en propuestas de leyes llevadas en su momento a las cámaras locales y federal por el Partido Católico Nacional; otras serían incluso confirmadas por la Constitución de $1917^{29}$.

\section{UN DEBATE SINGULAR EN TORNO A LA CUESTIÓN OBRERA}

El artículo 123 constitucional como lo conocemos ahora no estaba en el proyecto original de la Constitución. Fue durante las discusiones del artículo $5^{\circ}$, en las que se propusieron una serie de adicciones tendientes a proteger los derechos del trabajador, cuando se determinó que todas estas prerrogativas cabrían mejor en un lugar distinto que el de las garantías individuales.

Es interesante hacer ver que, aunque se vislumbraba la conveniencia de añadir unas disposiciones en ese sentido, a los partidarios de esta inclusión no les era del todo fácil fundamentar esa necesidad, como se puede apreciar en la siguiente explicación:

Juzgamos, asimismo, que la libertad de trabajo debe tener un límite marcado por el derecho de las generaciones futuras. Si se permitiera al hombre agotarse en el trabajo, seguramente que su progenie resultaría endeble y quizá degenerada, y vendría a constituir una carga para la comunidad. Por esta observación proponemos que se limiten las horas de trabajo y se establezca un día de descanso forzoso en la semana, sin que sea precisamente el domingo. Por una razón análoga creemos que debe prohibirse a los niños y a las mujeres el trabajo nocturno en la fábrica ${ }^{30}$.

El temor de ser comparados con los diputados del extinto Partido Católico Nacional llevaba a los miembros de la comisión a buscar puntos de apoyo verdaderamente extraños, al tiempo que a evitar cualquier propuesta que pudiera pensarse relacionada con los principios católicos, de ahí que se señalara que el día de des-

28 Cfr. Juan GONZÁLEZ MORFín, Labor pastoral del cuarto arzobispo de Guadalajara a la luz de su magisterio escrito, en Boletín eclesiástico, VII (2013/2), pp. 16-38.

29 Cfr. Jorge ADAME GODDARD, Influjo de la Doctrina..., op. cit., pp. 423-448.

$3023^{\text {a }}$ Sesión ordinaria, 26 de diciembre de 1926, punto 6. 
canso obligatorio no necesariamente tendría que ser el domingo ${ }^{31}$. La discusión de estos puntos se aplazó unos días, pues, «la comisión no desecha estos puntos de la citada iniciativa; pero no cree que quepan en la sección de las garantías individuales; así es que aplaza su estudio para cuando llegue al de las facultades del Congreso ${ }^{32}$.

Y, habiendo llegado el momento de abordar el tema, todavía habrían de surgir ironías en torno a la inspiración cristiana de aquello que se estaba proponiendo. Efectivamente, el diputado Rubén Martí se refirió a la iniciativa en tono por lo demás irónico: «Si no fuera porque sé que los principales miembros de la Comisión son individuos eminentemente liberales, les habría achacado la redacción de la poesía que leí en El Universal dedicada al señor don Atenógenes Silva ${ }^{33}$, porque encontré una conexión muy grande» ${ }^{34}$.

De manera análoga nos encontramos una propuesta del diputado López Lira $^{35}$ para adicionar el artículo 117 elevando a rango constitucional la prohibición de algunos «vicios», que fue recibida con aplausos, al tiempo que desechada. En esta, nuevamente se observa una cierta prevención a defender la moralidad de algunos actos (o la inmoralidad de otros), sin acudir argumentos «morales». Nuevamente se acude a tópicos difusos como la «fortaleza del individuo», o evitar su «degradación». Se presenta un extracto que permite apreciar lo que se presentaba como argumentos de peso:

Honorable Congreso: La experiencia constante y uniformemente repetida ha venido a ser ya una verdad axiomática que los pueblos triunfan única y exclusivamente cuando están constituidos por elementos fuertes capaces de influir directa o indirectamente en el progreso social.

De aquí ha resultado en las épocas modernas el empeño o esfuerzo de todos los gobiernos por combatir aquellas costumbres, hábitos o tendencias que llevan a la degradación o debilitamiento de los elementos componentes del cuerpo social; y,

31 Cuando en Jalisco el diputado Palomar y Vizcarra había propuesto legislar un día de descanso obligatorio en marzo de 1914, a la argumentación de la reparación de las fuerzas físicas había agregado la conveniencia de dedicar unas horas a atender la «vida del espíritu» (cfr. Francisco Barbosa GuZmán, Los trabajos legislativos del Partido Católico Nacional, Jalisco, 1912-1914, en II Fornada Académica Iglesia. Revolución Mexicana. El Partido Católico Nacional 1911-1914, Departamento de Estudios Históricos de la Arquidiócesis de Guadalajara / Universidad Autónoma de Guadalajara, Guadalajara, 2012, p. 135). Los diputados del Constituyente del 17, aun reconociendo la conveniencia de adoptar esa medida, buscaban distanciarse en la forma de proponerla.

$3223^{\text {a }}$ Sesión ordinaria, 26 de diciembre de 1926, punto 6.

33 Arzobispo de Michoacán, fallecido en 1911. Uno de los referentes en la defensa y promoción de los trabajadores. Mereció ser llamado «padre de los pobres».

$3423^{\text {a }}$ Sesión ordinaria, 26 de diciembre de 1926, punto 6.

35 Jesús López Lira, diputado por Guanajuato. 
por el contrario, de favorecer la creación y desarrollo de todos aquellos hábitos, usos $\mathrm{y}$ costumbres que se encaminan de una manera directa e inmediata a elevar el valor social del individuo (...).

Debe reconocerse también, en obsequio de la verdad y de la justicia, que la autoridad suprema de la revolución, con el aplauso de todos los buenos, ha procurado, a la vez que la extirpación del vicio del juego, la supresión de las corridas de toros; pero a pesar de esto, uno y otro vicio subsisten desgraciadamente y de seguro que subsistirán en lo futuro si un precepto constitucional no los prohíbe.

Debéis, pues, señores diputados, completar vuestra obra y, siguiendo el ejemplo que han dado muchos de los Estados de la Unión Norteamericana, establecer en la Constitución que vais a dar y que será la base sobre que se levantará el grandioso edificio del progreso mexicano, las medidas necesarias para extirpar los males que dejamos apuntados; de lo contrario, estad seguros, seguirá degenerándose el pueblo mexicano por el pulque y el mezcal, y seguirá haciéndose inútil la obra civilizadora, con el juego y con los espectáculos salvajes ${ }^{36}$.

Presenciamos así, dentro del mismo ámbito de los debates, una escalada cada vez con menos reparos para establecer un nuevo «clericalismo»: el clericalismo constitucionalista, que se atreve a presentar la necesidad de respetar una naturaleza humana, sin reconocer que exista, o de preservar coercitivamente al hombre de una serie de peligros «inmorales», sin reconocer expresamente la existencia de una ley moral. Una especie de religión alternativa, laica, con un lenguaje propio, con unas reglas propias y, desde luego, con sus propios dogmas ${ }^{37}$, que se presentara como una contrapartida, como una opción a la religión que mayoritariamente ostentaba el pueblo de México.

\section{LENGUAJE CLERICAL Y LENGUAJE ANTICLERICAL DE LOS DEBATES}

El lenguaje clerical, atendiendo a su etimología, se entendería como el propio del clero, es decir, aquel que los que pertenecen al estado clerical utilizan para exhortar, para llamar a obras buenas, para argumentar o, simplemente, aquel

$3657^{\text {a }}$ Sesión ordinaria, 23 de enero de 1917, punto 2.

37 De alguna manera, años más tarde, el presidente Obregón no tendría empacho en evidenciar esa postura en carta al episcopado mexicano en la que equipara al cristianismo con la propuesta revolucionaria: «Yo invito a ustedes con la sinceridad que caracteriza a los hombres de la Revolución y los exhorto para que, en bien de nuestros semejantes, no desvirtúen ni entorpezcan el desarrollo del programa esencialmente cristiano y esencialmente humanitario, por lo tanto, que el Gobierno surgido de la Revolución pretende desarrollar en nuestro país» (Álvaro OBREGÓN, Carta a fosé Mora y Leopoldo Ruiz y Flores, 23-I-1923, en ARCHIVO DE LA ARQUIDIÓCESIS DE MÉXICO, fondo episcopal: José Mora y del Río, caja 123, exp. 54). 
cuyos términos son propios de un ambiente de clérigos $^{38}$. De todas estas manifestaciones está imbuido el contenido de los debates. Por un lado, como ya se ha hecho notar, las argumentaciones han tenido que recurrir a ejemplos extraños, pero que concluyan, sin mencionarlo, en un reconocimiento de la dignidad de la persona humana, de la moralidad o, incluso, de una naturaleza humana. Así, por ejemplo, al quedar por fin constituido el constituyente, al hacer uso de la palabra para exhortar a sus compañeros diputados a trabajar de la mejor manera posible, el diputado por Jalisco Marcelino Dávalos ${ }^{39}$ no dudaba en repetir: $\ll_{i} E l$ ideal es el hombre! (...) ¡El ideal es el hombre! Desde mañana vamos a convertirnos en colaboradores de libertades; desde mañana no habrá disidencias de ningún género; ¡el ideal está enfrente y se llama la Constitución! jadelante, hacia el ideal! ¡adelante para salvarle, para hacerle vivir! $\gg^{40}$.

No hacen falta muchos señalamientos para alcanzar a ver en esta exhortación primeramente un reconocimiento expreso de la naturaleza humana, después una invitación que, en otro contexto, pudiera estar en un buen sermón sobre la convivencia y, todavía más, expresiones salvíficas más bien propias de una homilía. Y, poco antes que Dávalos, otro diputado, Cayetano Andrade ${ }^{41}$, peroraba de la siguiente manera: «En este mismo recinto se reunió el consejo de guerra que sentenció a muerte a los traidores y a ese príncipe de la barba rubia (...); vosotros, en este mismo recinto, decretad la muerte de la mentira y que surja esplendente la verdad para que, votando un código institucional adecuado a las necesidades del pueblo, lo presentéis con el corazón noble y limpio» ${ }^{42}$. Sobran comentarios sobre el estilo homilético.

$\mathrm{Al}$ mismo tiempo que se pugnaba porque resplandecieran valores universales como la verdad, se buscaban también otros como la higiene, que hasta el momento no había sido prioridad para otros gobiernos liberales, y se hacía ver cómo esta práctica era indispensable para tener un pueblo fuerte, pues Esparta, Grecia y otros pueblos «que antes que nada atendían a su constitución física» fueron su-

38 Esta peculiaridad de usar lugares comunes del clero al que pretendían erradicar, ya se venía usando por los liberales del siglo XIX y del porfiriato. Por ello, en el discurso político liberal se encontraban conceptos como el altar de la patria, los deberes sagrados con la nación, etc. (cfr. Nora PÉREZ RAYÓn, El anticlericalismo en México durante el Porfiriato. Modalidades, temas y manifestaciones, en María Marta PACHECO [coord.], Religión y sociedad en México durante el siglo XX, INEHRM, México, 2007, p. 80).

39 Marcelino Dávalos (1871-1923): Abogado, literato y editorialista nacido en Guadalajara.

$4011^{\text {a }}$ junta, 30 de noviembre de 1916, punto 20.

41 Diputado por Michoacán.

$4211^{\text {a }}$ junta, 30 de noviembre de 1916, punto 20. 
mamente poderosos, y «en Francia se toma también la higiene como uno de los puntos fundamentales, como algo que atañe directamente a la humanidad y algo que contribuye sobremanera para robustecer la raza». Y aquí, el orador citaba un pensamiento que al parecer procedía de un libro francés: «Decidme la cantidad de jabón que gastáis para vuestra limpieza y os diré el grado de civilización en que se encuentra el pueblo». Y terminaba afirmando: «un pueblo limpio (...) será grande y robusto» ${ }^{43}$.

Haciendo uso de este lenguaje clerical ${ }^{44}$ y paternalista, los constituyentes atacaron como vicios reprobables los juegos de azar en boga, las corridas de toros, los gallos y el alcoholismo, sobremanera condenado en distintos momentos: «contra estos vicios degeneradores de nuestro pueblo se ha hecho la actual revolución», señalaba el diputado por Jalisco Federico E. Ibarra, y añadía: «dar ahora a los mexicanos oportunidad para ir a gritar ordinarieces al coso taurino, solazarse con el martirio del toro o del gallo sacrificados; poner los naipes, dados, ruleta o lotería para que se robe a los incautos, es nulificar por completo las tendencias moralizadoras, educativas y progresistas de los legítimos revolucionarios ${ }^{45}$. Al final de una larga perorata, ampliamente aplaudida según señala el diario de los debates, el ingeniero Ibarra no perdió la oportunidad de hablar incluso de redención: «Por todo lo expuesto, señores diputados, me permito incitaros a que, cumpliendo con el compromiso revolucionario que tenemos, redimamos a nuestro pueblo, sacándolo de la abyección en que lo han sumido, combatiendo esos vicios... ${ }^{46}$.

Las invocaciones a la moral fueron utilizadas incluso para reprobar la disciplina de los ministros de culto del clero latino que permanecían célibes. Los constituyentes veían en esto una inmoralidad, pero, para no ser tachados de clericales, se sentían obligados a endulzar esa palabra con epítetos llamándola, por ejemplo, «moral según el criterio moderno», o bien, «moral entendida científicamente» ${ }^{47}$.

Se observa, pues, cómo los constituyentes, en momentos y asuntos diversos, acudían a un lenguaje más propio de un clérigo que de un parlamentario, aunque con una gran cantidad de prevenciones que los llevaba a justificarlo, sin darse quizá cuenta lo parecido de su conducta y modos de decir con aquellos que pretendían combatir.

$4350^{a}$ sesión ordinaria, 19 de enero de 1917 , punto 2.

44 Clerical en el sentido antes señalado, es decir, por el uso de tópicos más bien propios de los clérigos.

$4516^{\text {a }}$ sesión ordinaria, 18 de diciembre de 1916, punto 5 (el subrayado es nuestro).

46 Ibidem.

47 Véase, por ejemplo, la intervención del diputado por Durango, Alberto Terrones, en la $65^{\text {a }}$ sesión ordinaria, 27 de enero de 1917, punto 1. 
Y sobre este combate al clérigo, no tenían empacho en expresarlo abiertamente. Así, en la última junta previa a la instalación del pleno, luego de haber acordado los reglamentos para el proceso de elaboración de la nueva carta magna, el diputado por Michoacán, Francisco J. Múgica exhortaba: «Delenda est Cartago ${ }^{48}$, allí está el enemigo a quien destruir, porque allí está el enemigo a quien debemos hundirle hasta el pomo el puñal de la revolución» ${ }^{49}$.

Es sobreabundante la utilización de un lenguaje no únicamente despectivo, sino sobre todo agresivo y burdo para hacer referencia al clero, a la jerarquía eclesiástica, a la religión católica y, en algunos casos, incluso a otras confesiones, como a los protestantes ${ }^{50}$. Matute no duda en afirmar: «Los debates llevados a cabo en el seno del Congreso Constituyente celebrado en Querétaro en diciembre de 1916 y enero de 1917 representan el summum de la ideología anticlerical expresada en la revolución mexicana $\gg^{51}$. Los términos más duros y, en el lenguaje de hoy, más políticamente incorrectos, se vertieron durante los debates por la redacción definitiva de los que resultaron ser los artículos 24 y 130 constitucionales. De lo que se argumentaba en torno a este último, se citaran a continuación algunos fragmentos.

Por ejemplo, en una larga intervención del diputado José Álvarez, en la que entre otras cosas buscaba justificar la persecución que se había llevado a cabo hasta ese momento, el orador afirmaba lo siguiente:

Todos vosotros sabéis, señores diputados, que aquí no se ha perseguido a nadie porque profese determinada creencia; aquí se les ha perseguido porque eran enemigos del Gobierno de la revolución, porque sus doctrinas, sus prédicas y sus prácticas

48 «Cartago debe ser destruida», así exhortaba el tribuno Catón a los romanos del siglo II antes de Cristo para insistirles en la necesidad de aniquilar de una vez por todas a sus cercanos rivales del norte de África.

$4911^{\mathrm{a}}$ junta, 30 de noviembre de 1916, punto 20.

50 Aunque no es el objetivo de este trabajo ilustrar los ataques que también se dieron contra los protestantes, en mucho menor número que los dirigidos a la Iglesia católica, cabe citar que se dieron en un sentido de denuncia por una supuesta infiltración que culminaría con la conquista de México por los «yanquis». En esa línea sirve como ejemplo esta intervención de Félix F. Palavicini: «El mimetismo del sacerdote $(s i c)$ protestante es admirable: el sacerdote protestante ha organizado clubes de deportes que tienen toda la terminología inglesa, donde se hace música, se recitan malos versos, se baila el one step y de cuando en vez se abre la Biblia (...); pero no se detiene ahí el ministro protestante, que no puede distinguirse de los otros sacerdotes porque no lleva ni anillo episcopal, ni bonete, ni corona; sino que se infiltra en todos los establecimientos oficiales disfrazado de revolucionario radical (...); cobra con la mano derecha el sueldo de profesor laico, mientras con la mano izquierda recibe el dinero de las misiones protestantes de la República norteamericana, que es el precio para la evangelización de la República Mexicana y que es un aspecto de la conquista» (13 ${ }^{\text {a }}$ sesión ordinaria, 14 de diciembre de 1916, punto 8).

51 Álvaro MaTUTE, El anticlericalismo..., op. cit., p. 33. 
religiosas sólo eran la manera para llegar a apoderarse del Poder por ese mal llamado Partido Católico; de allí viene toda esa obra política que, amparada por la tolerancia del señor Madero, se desarrolló con tanta fuerza en aquella época; contra esa secta debemos luchar con toda energía, y yo no me explico en qué forma puede haber revolucionarios de buena intención que quieran que esos individuos que están actualmente en la línea divisoria, pendientes de nuestros actos, esperando que les abramos las puertas para volver a invadir otra vez la República, les digamos: pueden venir otra vez; la revolución ya triunfó en el campo de batalla; está la mesa puesta; vengan a despacharse. No, señores; sería una crueldad, una iniquidad contra los pueblos que no pueden defenderse de otra manera que volviéramos a permitir que (...) vinieran a chupar otra vez la sangre de nuestro pueblo ${ }^{52}$.

Como se puede ver, junto con un lenguaje ofensivo, se hace alusión a la fuerza que llegara a tener el Partido Católico, se critica la tolerancia de Madero y se invita a buscar los mecanismos para impedir el regreso de los obispos mexicanos, en su mayor parte desterrados en ese momento.

Junto con este tipo de explicaciones, en las que se trataba de justificar la persecución existente y la dureza de las disposiciones que se estaban proponiendo, existió también un discurso que prescindía de motivaciones y parecía que lo único que buscaba era ofender a un enemigo que ni estaba presente, ni en condiciones de hacer algo para defenderse. A este género pertenecen varias intervenciones de los diputados Francisco J. Múgica, Enrique Recio, José Álvarez, Modesto González Galindo y varios más.

En estas intervenciones no faltaron los apelativos de buitres, vampiros, etc., para referirse a los integrantes del clero. A manera de ejemplo se transcriben unas palabras que forman parte de una larguísima perorata del diputado José Álvarez:

Puesto que tenemos que legislar por una multitud de analfabetos que tiene que ser víctima, precisamente por su ignorancia, de las astucias de esos individuos explotadores, demos una ley prohibitiva, demos una ley que ponga a salvo nuestra nacionalidad, demos una ley en que no vayamos a entregarnos a esos buitres que dominan desde hace tiempo el alma popular, y hagamos comprender al pueblo que ellos han tratado de que no se instruya, para que pueda ser el eterno sufrido, para que en México pueda gobernar lo mismo un Porfirio Díaz que un Victoriano Huerta ${ }^{53}$.

$5265^{\text {a }}$ sesión ordinaria, 27 de enero de 1917, punto 3. Compárese con lo expuesto por el diputado por Nayarit Marcelino Cedano: «Yo creo que todavía está en el alma de todos los diputados presentes el recuerdo de aquel grupo formidable que pretendió reformarnos la legalidad por medio de la legalidad; que quería esgrimir la Constitución como arma de combate para demoler esa Constitución; que se amparaba con leyes liberales para luego darnos también el timo de liberalidad que nunca tuvieron...» (20 sesión ordinaria, 22 de diciembre de 1916, punto 4).

53 Ibidem. 
Así, lo mismo se vertían acusaciones como la anterior, que se estigmatizaba al clero romano por supuestamente obedecer a un soberano extranjero y se solicitaba a la asamblea dar «la primera clarinada» para «que el clero mexicano se declare independiente del papado» ${ }^{54}$, o bien, se recordaban como verdaderas hazañas las persecuciones acaecidas durante el ascenso al poder de los carrancistas, como la argumentación del diputado Francisco J. Múgica que se presenta a continuación:

Señores, se nos ha dicho que dentro de nuestro país no existe el problema religioso; es verdad, cada vez que la revolución, que los revolucionarios se han visto obligados a volar con las salvadoras bombas de mano algún edificio destinado al culto, jamás ha habido un grito de protesta entre nuestros hombres incultos, entre nuestros hombres rudos que han sido instrumento del clero para todas la ofuscaciones y maquinaciones del fanatismo, no se han arrepentido ni han vacilado un solo momento en penetrar al interior de un templo para matar a los enemigos de la libertad y para derribar esos edificios cuando ha sido necesario, sepultando en las ruinas y escombros de esos templos, al enemigo que se oponía al progreso salvador ${ }^{55}$.

Más adelante invitaría a la asamblea a dejar cualquier escrúpulo para aprobar el artículo 130 en sus términos más radicales, no sin antes volver a arremeter contra el clero llamándolo «banda de ladrones, forajidos y estafadores».

\section{A MODO DE CONCLUSIÓN}

En las discusiones consignadas en el Diario de los Debates del Congreso Constituyente se encuentran numerosas muestras de un anticlericalismo estridente y que, en determinados momentos, se jacta de tal manera de su radicalismo que fácilmente se le puede tildar de fanático, por más que se erigiera precisamente en defensor contra el fanatismo. Esa postura, al constituir un cuerpo cerrado en sí mismo de postulados «inobjetables» para quienes los sostenían, perfectamente se le puede calificar como una «ideología ${ }^{56}$, incluso, más que una ideología, en algunos momentos parece aspirar a convertirse en una nueva religiosidad que pretendiera sustituir con nuevos principios, dogmas y moral a la religión católica practicada por la mayoría de los mexicanos de la época.

54 Ibid. Intervención del ciudadano David Pastrana J., diputado por Puebla.

55 Ibid. Intervención del ciudadano Francisco J. Múgica, diputado por Michoacán.

56 Cfr. Álvaro MATUTE, El anticlericalismo..., op. cit., pp. 31 у 33. 
Esta nueva «religión laica», al proponer para lo sociedad principios y valores compartidos con la religión católica, a menudo tiene que argumentar con términos equívocos para conseguir defender, sin mencionar los postulados católicos o iusnaturalistas, los mismos efectos que ambos perseguían. Es una nueva «religiosidad» que pretende llamarse «científica», «positivista», «laica» o «racionalista» y que, aun evitando en lo posible los conceptos clásicos, no evade hablar de moralidad/inmoralidad y muchas veces acude a un lenguaje casi homilético para defender sus propuestas.

Por otro lado, la persecución todavía existente en el momento de los debates, y que se había de institucionalizar a través de algunas disposiciones antirreligiosas emanadas por el Constituyente, partía y tenía su justificación, según las intervenciones de los constituyentes más radicales, de una supuesta necesidad de suprimir el clero para que viva la revolución, evitando así que, con manifestaciones tolerantes hacia el clero como las que se tuvieron en el gobierno de Madero, fuera a resurgir un partido que dentro del marco legal pugnara por los ideales de la Iglesia, como lo fue en su momento el Partido Católico Nacional. De ahí un sinnúmero de intervenciones exhortando a los legisladores a no tener miedo a «hundir la espada», «exterminar esa hidra que se llama clero», «quitar la plaga del clericalismo» ${ }^{57}$, etc.

Otras premisas históricas e ideológicas de este anticlericalismo estridente han sido ya tratadas en otros estudios, particularmente en $\ll \mathrm{El}$ anticlerical revolucionario» Meyer propone diez claves, una de ellas la masonería y la liga a las formas religiosas que tomó el anticlericalismo ${ }^{58}$. En relación con esta, conviene solo asentar que «si bien no existen registros fiables sobre los constituyentes adscritos a una logia, algunos estudios perfilan hasta 74 de los 118 diputados en esta situación ${ }^{59}$.

57 Las dos primeras frases hacen alusión a intervenciones de Francisco J. Múgica; la última, a José Álvarez. Cabe señalar que ambos fueron compañeros en el seminario de Zamora (cfr. Jean MEYER, El anticlerical revolucionario..., op. cit., p. 290). En escritos periodísticos, anteriores a la Revolución, Múgica no disimula un lenguaje a todas luces clerical: «Si todos los hombres honrados se unen para buscar los mejores medios de engrandecimiento para su nación, es seguro que lograrán mejor sus fines, que cuando los perversos se congregan para hacer el mal (...). Los pueblos aman el bien por instinto, porque así gozan de bienestar y caminan presto al progreso y a la perfectibilidad, estado que es más grato a la criatura humana que el vicio y la degradación (Francisco J. MÚGICA, Luchar es vivir, artículo publicado en El Demócrata, citado en Francisco J. MúGICA, Hechos, no palabras, INEHRM, México, 1985, pp. 31-32).

58 Jean MEYER, El anticlerical revolucionario..., op. cit., p. 288.

59 Jorge Gaviño Ambriz, Prefacio, en Manuel JimÉnEZ GuZMán (coord.), Influencia de la Masonería en la Constitución de 1917, INEHRM, México, 2016, p. 15. 



\section{CRÓNICAS}


